\title{
ANÁLISE DE SUSTENTABILIDADE FINANCEIRA NO SEGMENTO IMOBILIÁRIO NA REGIÃO NORDESTE DE BELO HORIZONTE
}

\author{
FINANCIAL SUSTAINABILITY ANALYSIS RELATED TO REAL ESTATES IN \\ THE NORTHEAST REGION OF BELO HORIZONTE
}

\author{
Recebido: 07/12/2018 - Aprovado: 2/12/2019 - Publicado:02/01/2020 \\ Processo de Avaliação: Double Blind Review
}

\author{
Danilo Eustáquio de Oliveira Filho \\ https://orcid.org/0000-0002-3065-1977 \\ Centro Universitário Unihorizontes \\ daniloeoliveira@hotmail.com
}

\begin{abstract}
RESUMO: Este artigo tem como objetivo identificar quais as variáveis que influenciam na sustentabilidade dos negócios empresariais na percepção dos gestores. A sustentabilidade hoje nas empresas é uma ferramenta importante para seu crescimento e sobrevivência no longo prazo. Este estudo analisou como os gestores das imobiliárias trabalham com a sustentabilidade financeira e quais os seus resultados. Utilizou-se, primeiramente, a pesquisa bibliográfica, seguida por uma pesquisa quantitativa onde foi aplicado um questionário as imobiliárias dos bairros Dona Clara e Liberdade na cidade Belo Horizonte/MG. Esta pesquisa mostrou a importância das variáveis de sustentabilidade financeira com: planejamento financeiro, capital de giro e fluxo de caixa e como os gestores utilizam essas variáveis para que seu negócio seja sustentável financeiramente. $\mathrm{O}$ resultado desta pesquisa identificou que os gestores têm conhecimento sobre as variáveis que influenciam a sustentabilidade, mas mostrou também paradoxos na utilização destas variáveis.
\end{abstract}

Palavras Chave: Sustentabilidade Financeira. Planejamento. Capital de Giro. Gestão.

ABSTRACT: This article aims to identify the variables that influence the sustainability of business in the perception of managers. Sustainability today in companies is an important tool for their long-term growth and survival. This study analyzed how real estate managers work with financial sustainability and what their results are. A bibliographic research was first used, followed by a quantitative research where a questionnaire was applied to the real estate of the neighborhoods Dona Clara and Liberdade in the city Belo Horizonte/MG. This research showed the importance of financial sustainability variables with financial planning, working capital and cash flow and how managers use these variables to make their business financially sustainable. The result of this research identified that managers have knowledge about the variables that influence sustainability, but also showed paradoxes in the use of these variables.

Keywords: Financial Sustainability. Planning. Working capital. Management 


\section{INTRODUÇÃO}

Sustentabilidade é a capacidade de se auto sustentar, de se auto manter. Uma atividade sustentável qualquer é aquela que pode ser mantida por um longo período indeterminado de tempo, ou seja, para sempre, de forma a não se esgotar nunca, apesar dos imprevistos que podem vir a ocorrer durante esse período (FERNANDES, 2011).

Sendo assim, este estudo apresenta o seguinte problema de pesquisa: Como as imobiliárias de Belo Horizonte trabalham as variáveis de sustentabilidade financeira na percepção de seus gestores?

O objetivo geral deste estudo é identificar quais as variáveis que influenciam na sustentabilidade dos negócios empresariais na percepção dos gestores das imobiliárias localizadas nos bairros Dona Clara e Liberdade, na cidade de Belo Horizonte.

Para alcançar esse objetivo, foram definidos os seguintes objetivos específicos: descrever as características dos gestores das imobiliárias dos bairros Dona Clara e Liberdade, na cidade de Belo Horizonte/MG; descrever a percepção da importância das medidas de sustentabilidade financeira, relacionadas à gestão do capital de giro, planejamento financeiro e fluxo de caixa e apresentar, segundo autores, a importância da sustentabilidade financeira nos negócios.

Por isso, é muito importante a organização das finanças empresariais, incluindo planejamento financeiro, controle do capital de giro e o fluxo de caixa. Esses processos são essenciais para que o negócio dê rentabilidade resultando num empreendimento sustentável. Uma boa gestão financeira deve garantir sustentabilidade na empresa, gerando rentabilidade, caixa e sustentabilidade.

\section{SUSTENTABILIDADE}

A cada dia, o tema sustentabilidade ganha maior destaque nos meios empresariais, governamentais e acadêmicos, bem como na sociedade. Sucessivos fóruns internacionais vêm trabalhando e reiterando a preocupação com os modelos de desenvolvimento 
gestados no pós-guerra, onde supervalorizavam a dimensão econômica do desenvolvimento.

O termo sustentabilidade vem ganhando força desde 1972, com a Conferência sobre o Meio Ambiente Humano, em Estocolmo, que se originou o Programa das Nações Unidas para o Meio Ambiente - PNUMA, até os dias atuais, como a $16^{\mathrm{a}}$ Conferência sobre as Mudanças Climáticas que aconteceu no México, em 2011.

Para Amato Neto (2011), a visão socioeconômica de qualquer atividade produtiva deve ser economicamente viável e sustentável ao longo do tempo, isto é, qualquer empreendimento humano destinado à produção de bens e/ou serviços deve ser rentável.

Nas sociedades modernas, a produção desses bens e/ou serviços estão organizados a partir de empresas dos mais variados portes e nos mais variados setores da economia, considerando que essas empresas modernas, além de priorizar os seus objetivos econômicos, também realizam funções sociais ao gerar renda e emprego.

Segundo Claro, Claro e Amâncio (2008), o conceito de sustentabilidade mais difundido é o da Comissão Brundt-land (WCED,1987), a qual considera que o desenvolvimento sustentável deve satisfazer às necessidades da geração presente sem comprometer as necessidades das gerações futuras. Essa definição de desenvolvimento sustentável deixa claro que um dos princípios básicos de sustentabilidade é a visão de longo prazo, uma vez que os interesses das futuras gerações devem ser analisados.

No conceito de Mattarozzi (2002), a sustentabilidade é um paradoxo, ao mesmo tempo em que é fácil explicar o conceito e difícil de implementar, pois os agentes, como governo e empresas, devem fazer a gestão do desenvolvimento levando em consideração as dimensões ambiental, econômica e social segurando a perenidade da base natural.

A sustentabilidade exige uma lógica preventiva do empreendimento em si, pois o empreendimento apresentará pontos positivos e negativos. Os pontos positivos devem ser maximizados e valorizados e os pontos negativos minimizados e até mesmo desprezados.

Outro fator relevante na sustentabilidade é o avanço tecnológico que induz uma instabilidade econômica, social e ambiental, gerando a perda da diversidade natural e cultural. Os avanços tecnológicos que o homem foi capaz de obter tornaram cada vez mais curto o tempo para que um impacto sobre o meio ambiente e sobre a sociedade seja plenamente sentido (MATTAROZZI, 2002). 
A busca da sustentabilidade está relacionada diretamente com tempo, exigindo um planejamento perene capaz de contemplar o curto, médio e longo prazos, envolvendo todas as áreas da empresa.

Segundo Barbosa (2007), os três componentes fundamentais para o desenvolvimento sustentável são: crescimento econômico, proteção ao meio-ambiente e igualdade social (profit, planet and people), dando origem ao Triple Bottom Line.

O Triple Bottom Line, também conhecido em português como tripé da sustentabilidade organizacional, atende às necessidades do presente sem comprometer a capacidade das gerações futuras (NAKAGAWA, 2011).

\section{Figura 1 - Triple Bottom Line}

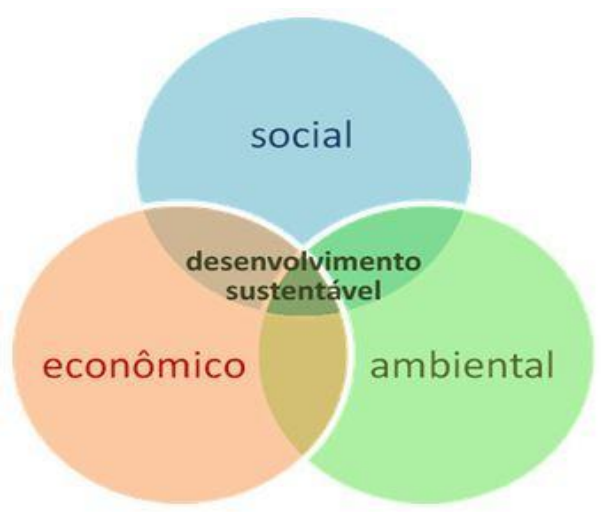

Fonte: Venturini e Lopes (2015, p.5).

As empresas passaram a efetuar inovação para a melhoria dos processos produtivos, a gerar valor na cadeia produtiva, alcance de um consumo consciente e por meio de um pós-consumo (VENTURINI; LOPES, 2015). O objetivo do Triple Bottom Line é reduzir os impactos ambientais, gerar valor e resolver os anseios sociais.

Para outros autores, como Landrum e Edwards (2009), os mesmos baseiam-se no conceito Triple Bottom Line para explicar que um negócio sustentável é aquele que opera sob o interesse de todos os atuais e futuros stakeholders, garantindo sobrevivência do negócio e de seus sistemas econômicos, sociais e ambientais. 
Em suma, pode-se afirmar que o envolvimento das empresas com as questões socioambientais pode se transformar em uma oportunidade de negócios, contribuindo para a melhoria de qualidade de vida dos stakeholders e a sustentabilidade dos recursos naturais.

\subsection{Sustentabilidade financeira}

Analisando o conceito de sustentabilidade e sua complexidade, no que tange aos campos ambiental, social e econômico, as empresas estão focadas em bater as suas metas para permanecer no mercado. Um dos principais eixos para as empresas se perpetuarem de formar sustentável no mercado é o financeiro. A sustentabilidade financeira é um importante pilar no que tange o Triple Bottom Line.

Fachini (2015) afirma que a sustentabilidade econômico-financeira acontece quando uma empresa consegue cobrir todos os seus custos, incluindo os de oportunidade e transação e permanece no mercado no longo prazo.

Para Fernandes e Meireles (2013), a sustentabilidade financeira consiste na habilidade das empresas de auto prover capital financeiro para responder às dificuldades consequentes da atividade econômica. Nesse mesmo sentido, os autores ainda propõem um modelo de indicador de sustentabilidade financeira onde a empresa auto provem os seus recursos financeiros para enfrentar contratempos. 


\section{Figura 2: Estrutura do Indicador de Sustentabilidade de uma empresa}

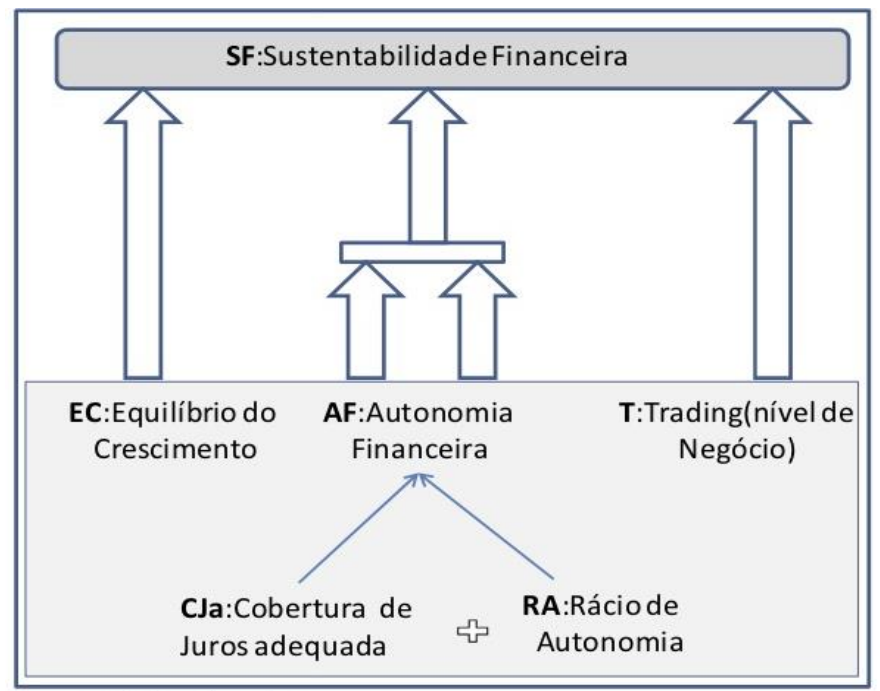

Fonte: Fernandes e Meireles (2013, p. 79).

O indicador de sustentabilidade financeiro é um indicador fundamentado em múltiplas variáveis como: autonomia financeira, equilíbrio do crescimento e trading (nível de negócio).

- A autonomia financeira significa a capacidade de resistência de uma empresa a contratempos operacionais.

- O equilíbrio do crescimento identifica a taxa de crescimento que uma empresa consegue sustentar com o seu fluxo de caixa operacional.

- Trading (nível de negócio) exprime a situação de recursos suficientes no balanço para a continuidade dos negócios.

Matias (2007), baseado no modelo de dimensões-chave do valor ao acionista elaborado por Hart e Milstein (2004), propõe um modelo de sustentabilidade financeira que as empresas devem seguir. Esse novo modelo deve manter o equilíbrio entre as entradas e saídas de recursos, com base na gestão do capital de giro na gestão familiar, na gestão de riscos operacionais e na geração de valor e competitividade 
Figura 3: Sustentabilidade financeira corporativa

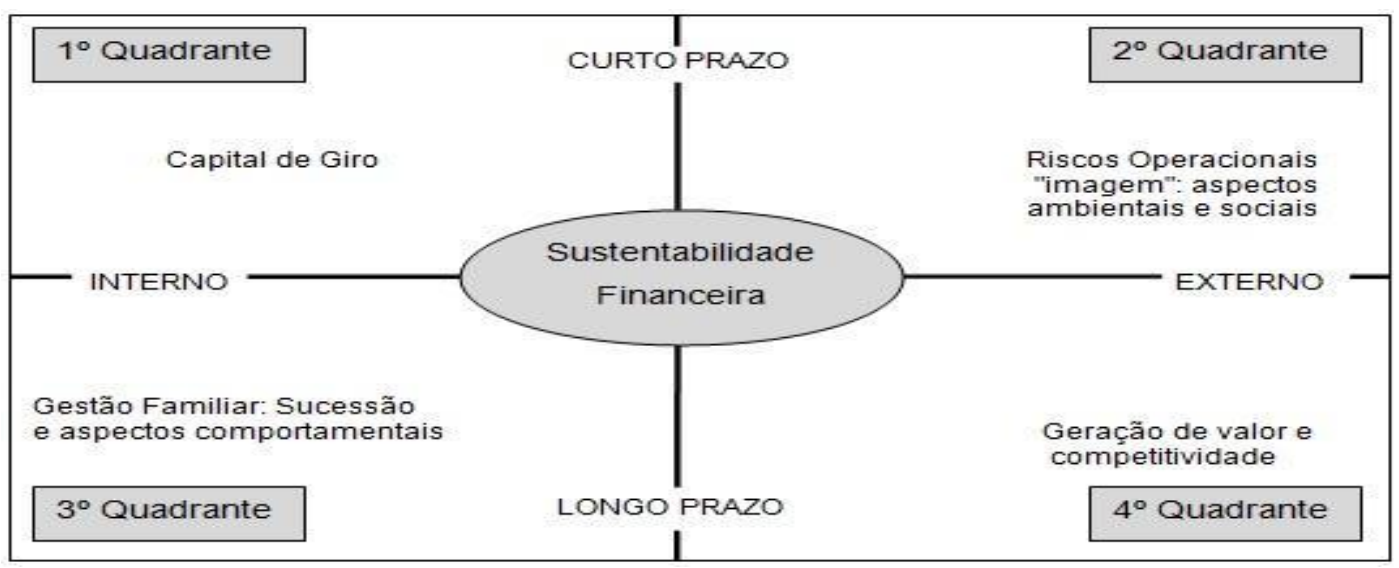

Fonte: Adaptada de Matias (2007b) apud Fonseca (2015, p. 29).

Contudo, Fonseca (2015) resume que o sucesso de um empreendimento está relacionado à habilidade e à capacidade do empreendedor de enxergar oportunidades e implementar ações para treinar e capacitar os colaboradores.

\subsection{Planejamento financeiro}

O planejamento financeiro de um negócio sustentável tende a ser semelhante a um negócio tradicional com a elaboração de orçamentos de investimentos, despesas e gastos de uma previsão do fluxo de caixa para os próximos anos (AMATO NETO, 2011). O planejamento financeiro é importante para que a empresa coordene suas atividades no presente e planeje seu futuro.

Para Oliveira (2014), o planejamento financeiro é o processo por meio do qual se calcula quanto de financiamento é necessário para se dar continuidade às operações de uma companhia e se decide quando e como a necessidade de fundos será financiada.

Por isso, o planejamento financeiro é o "pulmão" da empresa. Porque, através dele, as decisões serão tomadas tanto no curto e longo prazo, principalmente, em momentos de crises econômicas em que a empresa pode vir a precisar de financiamento.

Existem três tipos de planejamento financeiro: o primeiro visa o planejamento de longo prazo destinado às estratégias; o segundo é o de curto prazo, que está ligado diretamente aos dados operacionais e financeiros e o terceiro tipo de planejamento está ligado ao planejamento integral que interliga todos os planejamentos da empresa, 
interagindo as diversas áreas. Oliveira (2014) descreve que o planejamento de longo prazo é destinado às ações planejadas para um futuro distante, acompanhadas da previsão de seus reflexos financeiros. Esses planejamentos tendem a planejar períodos de dois a dez anos, sendo comum o emprego de planos quinquenais que são revistos periodicamente. Ainda, nesse tipo de planejamento, discutem-se os dispêndios de capital, atividades de pesquisa e desenvolvimento, ações de marketing e de desenvolvimento de produtos, estrutura de capital e importantes fontes de financiamento.

O planejamento de curto prazo são ações planejadas para um período curto (de um a dois anos) acompanhadas da previsão de seus reflexos financeiros (OLIVEIRA, 2014). Também são discutidos, nesse planejamento, a previsão de vendas, dados financeiros, orçamentos de caixa e demonstrações financeiras projetadas. Os planos de produção fazem parte, também, do curto prazo.

Já o planejamento integral vincula todos os planos de administração financeira aos planos de produção e de venda, bem como às atividades administrativas da empresa. Coordenando as forças de trabalho, uma vez que o planejamento integral requer principalmente o entrosamento da área financeira, com todas as demais áreas da empresa.

Verifica-se que um planejamento financeiro é um processo racional de administrar a renda, investimentos, despesas, patrimônio e suas dívidas, objetivando tornar realidade seus sonhos, desejos e objetivos (OLIVEIRA, 2014).

\subsection{Fluxo de caixa}

Devido à complexidade do mercado, a concorrência acirrada das empresas e o sistema econômico globalizado, as empresas devem ter um maior controle financeiro e acompanhamento de seus resultados avaliando instrumentos como desempenho e crescimento em tempo real.

Para Assaf Neto e Silva (2006), o fluxo de caixa é o instrumento que possibilita o planejamento e o controle dos recursos financeiros de uma empresa, sendo indispensável no processo de tomada de decisões financeiras. Nesse mesmo contexto, verifica-se a importância do fluxo de caixa, que mostra a entrada e a saída de recursos financeiros sinalizando o rumo dos negócios.

O fluxo de caixa abrange todas as áreas da empresa, como: área de produção devido alteração na produção; aérea de compras devido à existência de saldo para 
pagamento; área de cobrança para colocar recursos para dentro do caixa; área de vendas para aumentar os recursos disponíveis e, por último, a área financeira, que faz o controle geral conciliando todas as áreas com as entradas e saídas de recursos.

\subsection{Gestão do capital de giro}

O capital de giro tem participação relevante no desempenho operacional das empresas, cobrindo, geralmente, mais da metade de seus ativos totais investidos (ASSAF NETO; SILVA, 2006).

Segundo Fonseca (2015), no instante em que a organização entra em funcionamento, o gestor direciona sua atenção para esse elemento, porque a falta de controle das entradas e saídas de caixa ocasiona a mortalidade de muitas empresas.

O capital de giro engloba a administração do capital circulante que, por sua vez, engloba elementos que compõem as disponibilidades das organizações, como: créditos a receber, estoques e reservas monetárias (FONSECA, 2015). São recursos importantes para garantir o cumprimento das necessidades operacionais.

\section{Figura 4: Elementos de Giro}
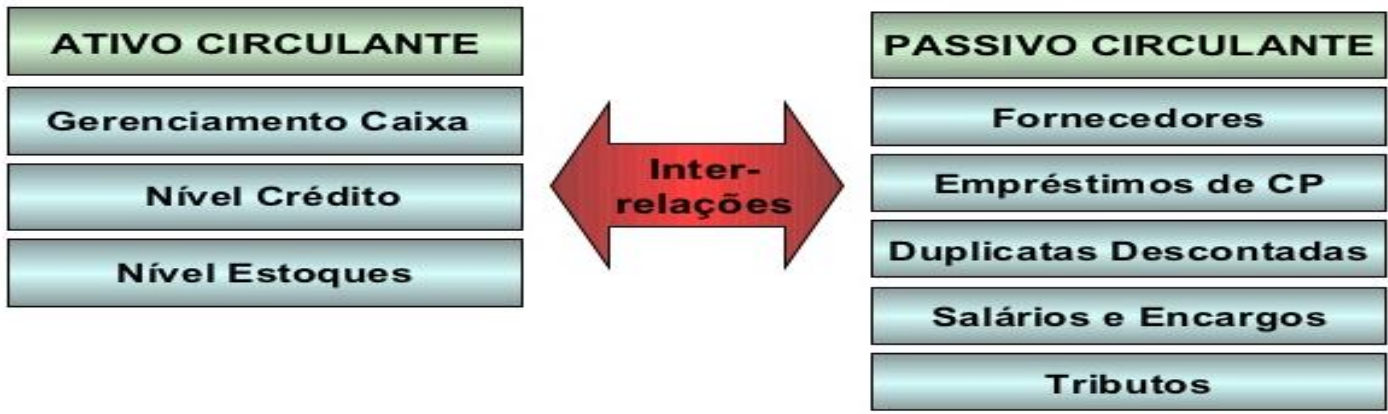

Fonte: Matias (2007a, p. 33).

É com base nas informações do capital de giro que as empresas formalizam estratégias operacionais de atuação, avaliando seus investimentos correntes e selecionando os passivos mais adequados (ASSAF NETO; SILVA, 2006).

Por isso, os gestores devem trabalhar com um plano de contingência, como forma de poder contar com ações estratégicas para superar situações que comprometam a estabilidade do capital de giro (MATIAS, 2007a). 
Matias (2007a) cita que alguns fatores como: sazonalidade, movimentos cíclicos da economia, aumento das vendas e a tecnologia influenciam a política de negócios da empresa, refletindo no volume do capital de giro. Como demonstrado na figura abaixo:

Figura 5: Volume do Capital de Giro

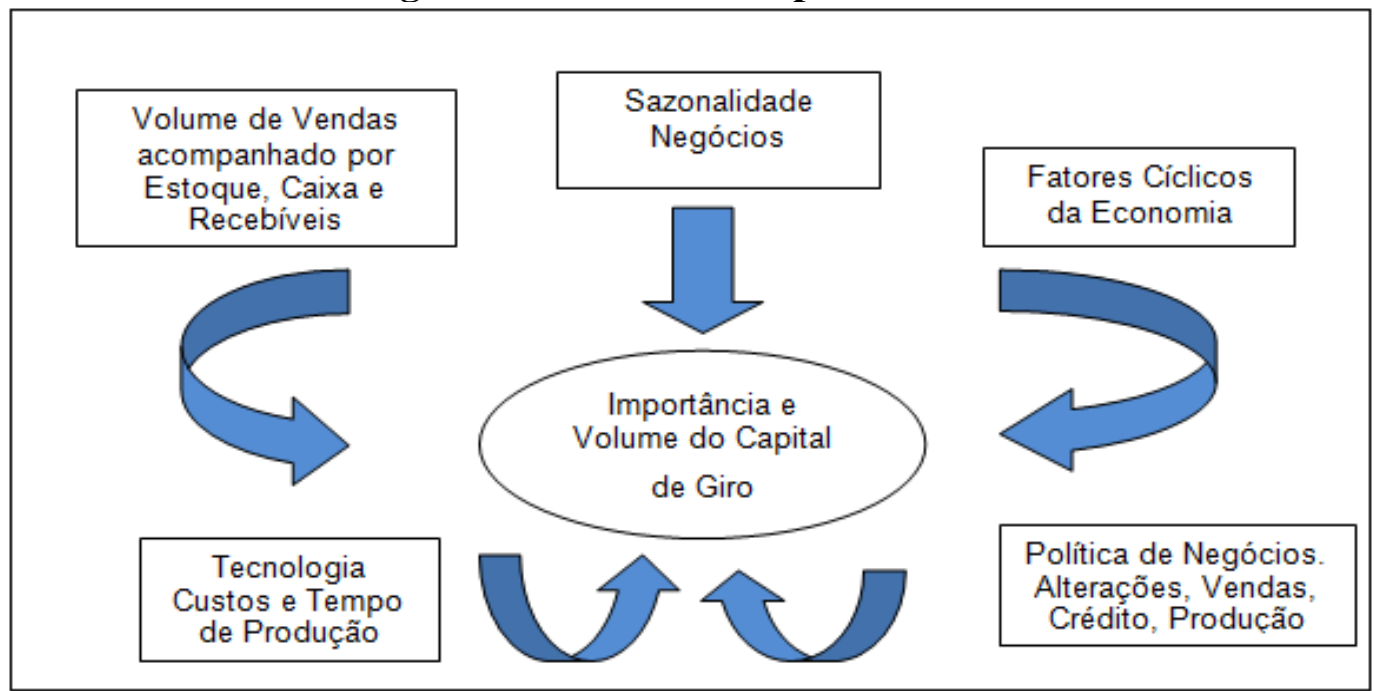

Fonte: Matias (2007a, p. 29).

A gestão do capital de giro é uma das mais importantes e complexas ferramentas das áreas financeiras da organização (MATIAS, 2007a). A gestão do capital de giro é a capacidade da firma em saldar seus compromissos de curto prazo, abordando as compras, fornecedores, salários, impostos, entre outros.

\subsection{Estudos anteriores sobre sustentabilidade}

Nesta seção, selecionamos os artigos e dissertações que contribuíram para este estudo e qual a sua importância e contribuição para as empresas, isto é, o quão é importante a sustentabilidade financeira.

Matias (2007b) afirma que o modelo usual do desenvolvimento sustentável enfoca os aspectos econômicos, sociais e ambientais e, que o valor da organização é avaliado pela perpetuidade, ou seja, os fluxos de caixa do futuro trazidos no agora. 
O Quadro 1 apresenta alguns estudos anteriores sobre sustentabilidade:

\section{Quadro 1 - Estudos sobre sustentabilidade}

\begin{tabular}{|c|c|c|}
\hline Título & Tipo & Conclusão Pesquisa \\
\hline $\begin{array}{l}\text { O planejamento financeiro como } \\
\text { mecanismo de sustentabilidade dos } \\
\text { empreendimentos informais da } \\
\text { economia solidária. }\end{array}$ & Artigo & $\begin{array}{l}\text { O artigo mostra que } 5 \text { dos } 13 \text { empreendimentos demonstraram } \\
\text { possuir sustentabilidade não apenas através da saúde financeira, mas } \\
\text { pela satisfação apresentada pelos associados em fazer partes do seu } \\
\text { empreendimento. }\end{array}$ \\
\hline $\begin{array}{l}\text { A importância do planejamento } \\
\text { financeiro }\end{array}$ & Artigo & $\begin{array}{l}\text { Com a falta de planejamento financeiro sólido pode causar falta de } \\
\text { liquidez podendo assim colocar em risco a continuidade da } \\
\text { organização. Objetivos e metas são necessários para organização. }\end{array}$ \\
\hline $\begin{array}{l}\text { Sustentabilidade financeira e custos de } \\
\text { transação em uma organização de } \\
\text { microcrédito no brasil. }\end{array}$ & $\begin{array}{l}\text { Dissertação de } \\
\text { Mestrado }\end{array}$ & $\begin{array}{l}\text { Os Custos de Transação influenciam a Sustentabilidade Financeira da } \\
\text { instituição de duas maneiras: por um lado os custos em relação às } \\
\text { receitas são altos o suficiente para tornar a instituição ainda } \\
\text { insustentável e, por outro lado, a maior parcela do custo de transação } \\
\text { diz respeito aos recursos humanos, que apresentam baixa } \\
\text { produtividade na expansão do crédito, o que gera um menor retorno } \\
\text { na carteira de crédito. }\end{array}$ \\
\hline $\begin{array}{l}\text { Entendendo o conceito de } \\
\text { sustentabilidade nas organizações. }\end{array}$ & Artigo & $\begin{array}{l}\text { O significado do termo sustentabilidade não é claro para a maioria } \\
\text { dos funcionários, o que impede a ocorrência de transformações } \\
\text { práticas e efetivas em prol da sustentabilidade. }\end{array}$ \\
\hline $\begin{array}{l}\text { Gestão empreendedora e fatores de } \\
\text { sustentabilidade financeira do pequeno } \\
\text { varejo supermercadista da região } \\
\text { metropolitana de belo horizonte. }\end{array}$ & $\begin{array}{l}\text { Dissertação de } \\
\text { Mestrado }\end{array}$ & $\begin{array}{l}\text { Pesquisados demonstraram que possuem consciência dos fatores } \\
\text { necessários à sustentabilidade financeira empresarial, porém, eles } \\
\text { ainda possuem uma visão de curto prazo. }\end{array}$ \\
\hline $\begin{array}{l}\text { O modelo triple bottom line e a } \\
\text { sustentabilidade na administração } \\
\text { pública: pequenas práticas que fazem a } \\
\text { diferença. }\end{array}$ & Artigo & $\begin{array}{l}\text { Por meio do estudo percebeu-se um bom entendimento conceitual na } \\
\text { administração pública sobre a temática, que há boas ideias, normas e } \\
\text { guias com ações práticas que podem ser executadas para esse alcance } \\
\text { da administração pública sustentável. }\end{array}$ \\
\hline $\begin{array}{l}\text { Sustentabilidade Financeira Empresarial } \\
\text { no Brasil. }\end{array}$ & $\begin{array}{l}\text { Dissertação de } \\
\text { Mestrado }\end{array}$ & $\begin{array}{l}\text { Os resultados contribuíram para o esclarecimento do tema e } \\
\text { permitiram a elaboração de um modelo teórico de Sustentabilidade } \\
\text { Financeira Empresarial, aplicável às empresas brasileiras. }\end{array}$ \\
\hline $\begin{array}{l}\text { Índice de sustentabilidade empresarial } \\
\text { da bolsa de valores de São Paulo (ISE- } \\
\text { Bovespa): exame da adequação como } \\
\text { referência para aperfeiçoamento da } \\
\text { gestão sustentável das empresas e para } \\
\text { formação de carteiras de investimento } \\
\text { orientadas por princípios de } \\
\text { sustentabilidade corporativa. }\end{array}$ & $\begin{array}{l}\text { Dissertação de } \\
\text { Mestrado }\end{array}$ & $\begin{array}{l}\text { Índice atende às necessidades dos investidores que desejam alocar } \\
\text { recursos numa carteira de ações listadas na bolsa de São Paulo e } \\
\text { baseada em princípios de sustentabilidade corporativa. }\end{array}$ \\
\hline
\end{tabular}

Fonte: Elaborado pelo autor.

O quadro acima mostra, de forma resumida, a importância do tema sustentabilidade para as empresas se perpetuarem no mercado. Tantos os artigos como as dissertações concluem que a sustentabilidade financeira é o "pulmão" das empresas, enfatizando variáveis como planejamento financeiro, fluxo de caixa e capital de giro que iram orientar os gestores nas tomadas de decisões no curto, médio e longo prazos.

Vimos, também, que as ideias sobre a sustentabilidade vêm ganhando força nas empresas públicas e privadas, apesar de algumas empresas ainda acharem que esses custos de formação para suas equipes ficam caros mas, na realidade, são custos que beneficiam não somente os funcionários mas sim a empresa, uma vez que a equipe direcionada para sustentabilidade, também direciona a empresa para o sucesso. 
A sustentabilidade organizacional precisa ser observada em todos os departamentos da empresa de maneira conjunta para que não haja a destruição de valor na soma dos resultados (MATIAS, 2007b).

\section{METODOLOGIA}

O tipo de pesquisa adotado é a descritiva. As pesquisas descritivas são estruturadas e especificamente criadas para medir as características descritas em uma questão de pesquisa (HAIR JR. et al. 2005).

$\mathrm{Na}$ pesquisa descritiva procura-se, também, identificar opiniões, situações ou atitudes evidenciadas em uma população, expõe a distribuição de um determinado fenômeno na população e desempenha a comparação entre essas distribuições, além de avaliar se a percepção dos acontecimentos está ou não em conformidade com a realidade (FREITAS et al., 2000). Para o método da pesquisa, foi escolhido a survey que, segundo Hair Jr. et al. (2005), a survey é um mecanismo para coleta de dados primários a partir de indivíduos e os dados podem variar de acordo com o assunto pesquisado.

Os métodos da coleta de dados de survey são divididos em duas categorias, sendo o questionário e a entrevista. Para Marconi e Lakatos (2010), o questionário é um instrumento de coleta de dados, constituído por uma série ordenada de perguntas, que devem ser respondidas por escrito e sem a presença do entrevistador.

O universo desta pesquisa serão todas as imobiliárias dos bairros Dona Clara e Liberdade, na cidade de Belo Horizonte/MG, totalizando 25 (vinte e cinco) imobiliárias. A amostra definida para esta pesquisa foi: 18 (dezoito) imobiliárias que responderam o questionário. 


\section{ANÁLISE DE DADOS}

$\mathrm{Na}$ interpretação dos dados da pesquisa, enfatizou-se os aspectos que foram perceptíveis à luz do embasamento teórico do estudo, da mesma forma que aqueles analisados a partir da pesquisa de natureza quantitativa.

A pesquisa foi dividida em 3 partes, sendo a primeira parte em uma estatística descritiva contendo dados sócio demográficos, a segunda parte informações gerais das imobiliárias e a terceira parte levantamento das percepções e medidas empresariais dos gestores das imobiliárias.

A amostra pesquisada é quase homogênea com relação ao gênero, não obstante, a maioria é do gênero masculino, sendo que a maior parte dos respondentes tem entre 40 e 59 anos de idade. No que tange ao grau de instrução dos respondentes, a maioria possui ensino superior completo. O cargo ocupado pela maioria dos respondentes é de administração, sendo que a maioria é sócio da organização.

É possível identificar que se predomina na amostra empresas com mais de 15 anos de existência legal. No que tange ao faturamento das empresas, nenhuma está em fase pré-operacional, predominando empresas com faturamento médio anual de até R \$ 300 mil, sendo que 39\% delas possui faturamento acima de $\mathrm{R} \$ 101$ mil por ano.

A fim de ponderar as percepções sobre a gestão do capital de giro, foram estabelecidos quatro quadrantes: empréstimo, prazo, gestão e investimento, sob os quais são analisadas estatisticamente as respostas, conforme disposto na Tabela 1: 
Tabela 1 - Gestão de Capital de Giro

\begin{tabular}{|c|c|c|c|c|c|c|c|c|c|}
\hline Quadrante & Questionamento & Média & $\begin{array}{l}\text { Desv. } \\
\text { Pad. }\end{array}$ & Q. 25 & Q. 50 & Q. 75 & Sim & Não & $\begin{array}{c}\text { Não } \\
\text { respondeu }\end{array}$ \\
\hline \multirow[t]{2}{*}{ Empréstimo } & $\begin{array}{l}\text { Uma empresa só deve contratar } \\
\text { empréstimo para capital de giro } \\
\text { enquanto o custo financeiro do } \\
\text { dinheiro empatado para o } \\
\text { financiamento desses estoques } \\
\text { estiver abaixo do lucro na venda de } \\
\text { seus produtos }\end{array}$ & 3,778 & 1,215 & 3 & 4 & 5 & - & - & - \\
\hline & $\begin{array}{l}\text { Já contratou empréstimos para } \\
\text { capital giro? }\end{array}$ & - & - & - & - & - & 6 & 12 & 0 \\
\hline \multirow[t]{2}{*}{ Prazo } & $\begin{array}{l}\text { A divulgação por meio de ofertas } \\
\text { para o incentivo de vendas é uma } \\
\text { ação que exige um volume } \\
\text { considerável de investimento nos } \\
\text { produtos/serviços que serão } \\
\text { ofertados, assim o capital de giro } \\
\text { necessário deve ser negociado com } \\
\text { maiores prazos de pagamento junto } \\
\text { aos fornecedores }\end{array}$ & 4,056 & 1,305 & 3,25 & 5 & 5 & - & - & - \\
\hline & $\begin{array}{l}\text { Negocia com fornecedores maiores } \\
\text { prazos para realização de ações de } \\
\text { marketing? }\end{array}$ & - & - & - & - & - & 12 & 5 & 1 \\
\hline Gestão & $\begin{array}{l}\text { A gestão inadequada do capital de } \\
\text { giro é um dos principais motivos para } \\
\text { o fechamento de empresas no Brasil } \\
\text { e uma possível explicação para esse } \\
\text { fato é a fragilidade dos registros } \\
\text { contábeis e também, do nível de } \\
\text { controle gerencial nessas empresas. }\end{array}$ & 4,111 & 1,451 & 4 & 5 & 5 & - & - & - \\
\hline \multirow[t]{2}{*}{ Investimento } & $\begin{array}{l}\text { Para a sobrevivência da pequena } \\
\text { empresa é necessário continuamente } \\
\text { melhorar suas instalações e serviços } \\
\text { fornecidos para o cliente, exigindo } \\
\text { investimentos constantes, que em } \\
\text { muitos casos são buscados junto às } \\
\text { instituições que financiam recursos } \\
\text { em longo prazo. }\end{array}$ & 3,444 & 1,338 & 3 & 4 & 4 & - & - & - \\
\hline & $\begin{array}{l}\text { Já contratou empréstimos para } \\
\text { investimentos junto a instituições de } \\
\text { fomento (BNDES, BDMG, Outro)? }\end{array}$ & - & - & - & - & - & 1 & 17 & 0 \\
\hline
\end{tabular}

Fonte: Dados da pesquisa (2018).

Com relação ao quadrante empréstimo, identificou-se que predominantemente ( $\overline{\mathrm{X}}=3,778$ com $\delta=1,215$ ) os respondentes concordam que o empréstimo para capital de giro somente é factível enquanto o custo financeiro do dinheiro empatado para o financiamento desses estoques (imóveis) estiver abaixo do lucro na venda de seus produtos/serviços. Vale ressaltar que existe certa tendência de considerarem esse aspecto como indiferente à sua realidade empresarial. Identificou-se, também, que a maioria (67\%) não contraiu empréstimo com a finalidade de capital de giro, o que, provavelmente, corrobora com a resposta sobre a contratação de empréstimo para capital de giro, uma 
vez que consideram relevante esse empréstimo apenas em caso de custo de estoques elevados em relação ao lucro.

No que tange ao quadrante prazo, os respondentes eminentemente ( $\bar{X}=4,056 \mathrm{com}$ $\delta=1,305)$ concordam que o capital de giro necessário deve ser negociado com maiores prazos de pagamento junto aos fornecedores ao investir nos produtos/serviços a fim de estabelecer divulgação por meio de ofertas para o incentivo de vendas. Nesse aspecto, a maioria $(71 \%)$ dos respondentes afirma que negocia com fornecedores maiores prazos para realização de ações de marketing.

O quadrante gestão apresentou que, preeminentemente ( $\bar{X}=4,111$ com $\delta=1,451)$, os respondentes concordam plenamente que a gestão inadequada do capital de giro é um dos principais motivos para o fechamento de empresas no Brasil e, uma possível explicação para esse fato, é a fragilidade dos registros contábeis e, também, do nível de controle gerencial nessas empresas. Apesar da maioria concordar que os registros contábeis inadequados podem fechar as empresas, o desvio padrão nos mostra uma dispersão desses gestores em relação à média.

Por fim, no quadrante investimento, identificou-se que os respondentes concordam, predominantemente $(\bar{X}=3,444$ com $\delta=1,338)$ que para a sobrevivência da pequena empresa é necessário continuamente melhorar suas instalações e serviços fornecidos para o cliente, exigindo investimentos constantes que, em muitos casos, são buscados junto às instituições que financiam recursos em longo prazo. Ressalta-se que existe certa tendência de considerarem esse aspecto como indiferente à sua realidade empresarial, com base nos resultados apresentados na Tabela 1. Não obstante, a grande maioria (94\%) não contratou empréstimos para investimentos junto às instituições de fomento (BNDES, BDMG, outros).

Ainda, identificou-se que a grande maioria dos respondentes $(83 \%)$ possui controle do fluxo de caixa e com tempo predominante (55\%) entre 16 e mais de 180 dias (excluindo-se os intervalos de "121 a 180 dias"; "de 31 a 60 dias"; "de 61 a 90 dias"; e “de 8 a 15 dias"), sendo mais relevante o prazo de 16 a 30 dias no controle do fluxo de caixa (33\%), conforme apresentado no Gráfico 1: 


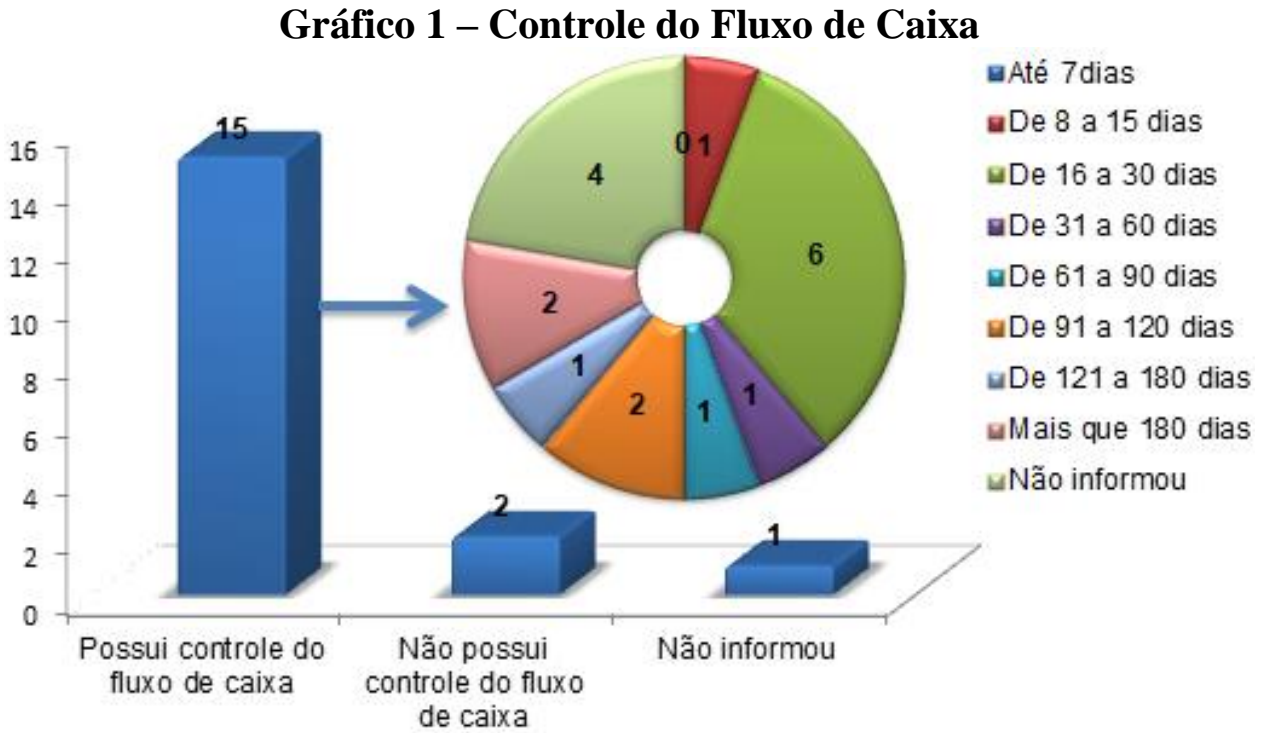

Fonte: Dados da pesquisa (2018).

A fim de ponderar as percepções sobre a gestão de riscos operacionais relacionados à imagem e aos aspectos ambientais e sociais, foram estabelecidos dois quadrantes (perdas e responsabilidade social ambiental - RSA), sob os quais são analisadas estatisticamente as respostas, conforme disposto na Tabela 2:

Tabela 2 - Gestão de riscos operacionais relacionados à imagem e aos aspectos ambientais e sociais

\begin{tabular}{|c|c|c|c|c|c|c|c|c|c|}
\hline Quadrante & Questionamento & Média & $\begin{array}{l}\text { Desv. } \\
\text { Pad. }\end{array}$ & Q. 25 & Q. 50 & Q. 75 & Sim & Não & $\begin{array}{c}\text { Não } \\
\text { respondeu }\end{array}$ \\
\hline \multirow[t]{2}{*}{ Perdas } & $\begin{array}{l}\text { A possibilidade de perda financeira } \\
\text { decorrente de riscos de crédito, riscos de } \\
\text { mercado e risco operacional (perdas } \\
\text { decorrentes de fraudes e falhas de } \\
\text { equipamentos, sistemas, pessoas, processo } \\
\text { ou eventos externos) é clara e um bom } \\
\text { gerenciamento desse risco deve resultar em } \\
\text { um plano de contingência prevendo as } \\
\text { estratégias a serem usadas para assegurar } \\
\text { condições de continuidade das atividades e } \\
\text { para limitar as perdas decorrentes do risco } \\
\text { operacional }\end{array}$ & 4,056 & 1,514 & 4,000 & 5,000 & 5,000 & - & - & - \\
\hline & $\begin{array}{l}\text { A empresa possui um planejamento para } \\
\text { contingência para cobrir perdas inesperadas? }\end{array}$ & - & - & - & - & - & 10 & 8 & 0 \\
\hline \multirow[t]{2}{*}{ RSA } & $\begin{array}{l}\text { As empresas estão buscando apresentar uma } \\
\text { imagem responsável em questões sociais e } \\
\text { ambientais e a pequena empresa pode fazer } \\
\text { isso por meio de prestação de serviços de } \\
\text { qualidade, bons preços, atendimento } \\
\text { personalizado à comunidade e com o } \\
\text { mínimo de dano ao meio ambiente. }\end{array}$ & 4,611 & 0,778 & 4,250 & 5,000 & 5,000 & - & - & - \\
\hline & $\begin{array}{l}\text { A empresa possui um plano formal de } \\
\text { relacionamento com a comunidade? }\end{array}$ & - & - & - & - & - & 8 & 10 & 0 \\
\hline
\end{tabular}

Fonte: Dados da pesquisa (2018). 
O quadrante perdas apresentou que, preeminentemente $(\bar{X}=4,056$ com $\delta=1,514)$, os respondentes concordam plenamente que um bom gerenciamento do risco de perda financeira decorrente de riscos de crédito, riscos de mercado e risco operacional deve resultar em um plano de contingência, prevendo as estratégias a serem usadas para assegurar condições de continuidade das atividades e para limitar as perdas decorrentes do risco operacional. O desvio padrão dessa questão também nos mostra que que há uma dispersão ao longo da média. Já $56 \%$ das empresas pesquisadas possuem um planejamento para contingência para cobrir perdas inesperadas.

E com relação ao quadrante RSA, identificou-se que os respondentes concordam plenamente ( $\bar{X}=4,611$ com $\delta=0,778)$ que as empresas estão buscando apresentar uma imagem responsável em questões sociais e ambientais e a pequena empresa pode fazer isso por meio de prestação de serviços de qualidade, bons preços, atendimento personalizado à comunidade e com o mínimo de dano ao meio ambiente. O desvio padrão dessa questão apresenta um número de gestores mais homogêneo, ou seja, quando se trata de questões sociais e ambientais todos confirmam a importância desses serviços prestados à comunidade. Não obstante, $56 \%$ das empresas pesquisadas não possuem um plano formal de relacionamento com a comunidade.

A fim de ponderar as percepções sobre a gestão familiar, foram estabelecidos seis Quadrantes (Missão, Visão e Valores; Separação do Patrimônio; Gerações; Planejamento Estratégico; Vantagem Competitiva; Competitividade), sob os quais são analisadas estatisticamente as respostas, conforme disposto na Tabela 3. 
Tabela 3 - Gestão familiar: sucessão e aspectos comportamentais

\begin{tabular}{|c|c|c|c|c|c|c|c|c|c|}
\hline Quadrante & Questionamento & Média & $\begin{array}{l}\text { Desv. } \\
\text { Pad. }\end{array}$ & Q. 25 & Q. 50 & Q. 75 & Sim & Não & $\begin{array}{l}\text { Não } \\
\text { respondeu }\end{array}$ \\
\hline \multirow[t]{3}{*}{$\begin{array}{l}\text { Separação do } \\
\text { Patrimônio }\end{array}$} & $\begin{array}{l}\text { Para se ter uma boa governança familiar } \\
\text { deve-se considerar primeiramente a } \\
\text { separação do patrimônio pessoal do } \\
\text { patrimônio empresarial, assim como ter } \\
\text { a compreensão da dinâmica familiar e a } \\
\text { sua não interferência na gestão } \\
\text { administrativa do negócio. }\end{array}$ & 4,833 & 0,383 & 5,000 & 5,000 & 5,000 & - & - & - \\
\hline & $\begin{array}{l}\text { É clara na empresa a divisão entre o } \\
\text { patrimônio da empresa e da família? }\end{array}$ & - & - & - & - & - & 17 & 1 & 0 \\
\hline & $\begin{array}{l}\text { São quitadas dividas pessoais dos sócios } \\
\text { na conta da empresa? }\end{array}$ & - & - & - & - & - & 6 & 11 & 1 \\
\hline \multirow[t]{2}{*}{$\begin{array}{l}\text { Planejamento } \\
\text { Estratégico }\end{array}$} & $\begin{array}{l}\text { O Planejamento Estratégico é uma fonte } \\
\text { de reflexão para a organização e visto } \\
\text { como um instrumento para repensar } \\
\text { processos, atividades e produtos, sua } \\
\text { utilização favorece a inovação e a } \\
\text { sustentabilidade financeira. }\end{array}$ & 4,500 & 1,200 & 4,250 & 5,000 & 5,000 & - & - & - \\
\hline & $\begin{array}{l}\text { A empresa possui plano estratégico } \\
\text { formal? }\end{array}$ & - & - & - & - & - & 7 & 11 & 0 \\
\hline \multirow[t]{2}{*}{ Competitividade } & $\begin{array}{l}\text { O desempenho de uma empresa será } \\
\text { condicionado por um conjunto de fatores } \\
\text { que implicam na sua competitividade. A } \\
\text { competitividade, por sua vez, não é } \\
\text { estática, mas dinâmica, já que esses } \\
\text { fatores estão em constante processo de } \\
\text { mudança. O desempenho e eficiência, } \\
\text { por sua vez, serão consequências do } \\
\text { ajuste da empresa ao mercado, à } \\
\text { concorrência, ao ambiente econômico } \\
\text { em que ela está inserida e a boa gerencia } \\
\text { de suas atividades. }\end{array}$ & 4,944 & 0,236 & 5,000 & 5,000 & 5,000 & - & - & - \\
\hline & $\begin{array}{l}\text { A empresa possui consciência dos } \\
\text { principais fatores que implicam sua } \\
\text { competitividade? }\end{array}$ & - & - & - & - & - & 17 & 1 & 0 \\
\hline
\end{tabular}

Fonte: Dados da pesquisa (2018).

O quadrante separação do patrimônio apresentou que os respondentes concordam plenamente ( $\bar{X}=4,833$ com $\delta=0,383$ ) que para se ter uma boa governança familiar devese considerar primeiramente a separação do patrimônio pessoal do patrimônio empresarial, assim como ter a compreensão da dinâmica familiar e a sua não interferência na gestão administrativa do negócio. Noventa e quatro por cento das empresas pesquisadas possuem divisão entre o patrimônio da empresa e da família. Não obstante, em 35\% das empresas pesquisadas, as dívidas pessoais dos sócios são quitadas na conta da empresa.

$\mathrm{O}$ quadrante planejamento estratégico apresentou que, preeminentemente $(\overline{\mathrm{X}}$ $=4,500 \operatorname{com} \delta=1,200$ ), os respondentes concordam que o planejamento estratégico é uma fonte de reflexão para a organização e visto como um instrumento para repensar processos, atividades e produtos, sua utilização favorece a inovação e a sustentabilidade financeira. Não obstante, $61 \%$ das empresas pesquisadas não possuem um plano 
estratégico formal. Essa porcentagem é confirmada quando se verifica o desvio padrão da questão que apresenta um número alto em relação à média, concluindo que nem todo os gestores têm conhecimento da importância do planejamento estratégico.

Por fim, no que tange ao quadrante competitividade, os respondentes concordam plenamente ( $\overline{\mathrm{X}}=4,944$ com $\delta=0,236)$ que o desempenho e eficiência, por sua vez, serão consequências do ajuste da empresa ao mercado, à concorrência, ao ambiente econômico em que ela está inserida e a boa gerência de suas atividades. Em consonância a esse resultado, $94 \%$ das empresas pesquisadas possuem consciência dos principais fatores que implicam sua competitividade.

\section{CONSIDERAÇÕES FINAIS}

A pergunta norteadora do estudo foi no sentido de identificar se as variáveis de sustentabilidade financeira influenciam a sustentabilidade financeira das imobiliárias e a percepção dos gestores. Inicialmente, na elaboração do estudo, apontamos ferramentas importantes de gestão que contribuem para uma sustentabilidade financeira eficaz.

As variáveis, como: planejamento financeiro, capital de giro e fluxo de caixa são ferramentas eficazes para o crescimento, prevenção e longevidade do negócio. Os gestores devem utilizá-las frequentemente de modo a auxiliá-los em tomada de decisões no curto, médio e longo prazos. Uma empresa sustentável toma decisão no curto prazo levando em consideração as consequências no futuro.

O desenvolvimento sustentável deve satisfazer às necessidades da geração presente sem comprometer as necessidades das gerações futuras (CLARO; CLARO; AMÂNCIO, 2008). A sustentabilidade hoje nas empresas é fundamental na sua sobrevivência no futuro, uma vez, que as tomadas de decisões hoje são consequências de sucesso no amanhã.

A sustentabilidade econômico-financeira acontece quando uma empresa consegue cobrir todos os seus custos, incluindo os de oportunidade e transação e permanece no mercado no longo prazo (FACHINI, 2015). Para Fernandes e Meireles (2013), a sustentabilidade financeira consiste na habilidade das empresas de auto prover capital 
financeiro para responder às dificuldades consequentes da atividade econômica. $\mathrm{Na}$ pesquisa realizada, o quadrante empréstimo na Tabela 1 corrobora com os autores, pois a maioria dos gestores responderam que o empréstimo só é factível quando estiver com custo baixo e, que de $67 \%$ dos respondentes não contraiu empréstimo, o que nos leva crer que o empréstimo só é necessário quando as vendas caírem e seus estoques estiverem altos, existindo aí uma coerência sobre o endividamento.

Outra variável importante da sustentabilidade nas empresas é o fluxo de caixa. Quando a empresa inicia seus negócios, o fluxo já deve existir para nortear as tomadas de decisões. O fluxo de caixa é um instrumento que relaciona os ingressos e saídas de recursos financeiros de uma empresa, prognosticando eventuais excedentes ou escassez de caixa (ASSAF NETO; SILVA, 2006). Esse conceito também é confirmado pela pesquisa. Quando perguntado aos gestores se os mesmos faziam o fluxo de caixa, 83\% dos respondentes responderam que sim. Conclui-se a importância de um fluxo de caixa na empresa, informando aos gestores a entrada e a saída de recursos, prevenindo eventuais perdas.

Outra questão abordada na pesquisa foi as perdas financeiras, e a pesquisa mostrou que somente $56 \%$ dos gestores apresentam um planejamento para contingência financeira. Número baixo em si tratando de perdas para as empresas. Por isso, um bom planejamento financeiro é essencial e importante para que a empresa coordene suas atividades no presente e planeje seu futuro. O capital de giro, como instrumento de sustentabilidade financeira, desempenha papel importante na vida das empresas.

\section{REFERÊNCIAS}

ALMEIDA, Fernando. O bom negócio da sustentabilidade. Rio de Janeiro: Nova Fronteira, 2002.

ARAUJO, Vagner Dória; SANTANA, José da Conceição. O planejamento financeiro como mecanismo de sustentabilidade dos empreendimentos informais da economia solidária. Gestão e Planejamento. Universidade de Salvador-UNIFACS, v.16, n. 1, 2015. Disponível em: <https://revistas.unifacs.br/index.php/rgb/article/view/3199>. Acesso em: 26 set. 2018. 
ASSAF NETO, Alexandre; SILVA, Cesar Augusto Tibúrcio. Administração do Capital de Giro. 3. ed. São Paulo: Atlas, 2002.

BACHA, Maria de Lourdes; SANTOS, Jorgina; SCHAUN, Ângela. Considerações teóricas sobre o conceito de Sustentabilidade. VII Simpósio de Excelência em Gestão e Tecnologia - SEGeT, 2010.

BARBOSA, Paulo Roberto Arcoverde. Índice de sustentabilidade empresarial da bolsa de valores de São Paulo (ISE-Bovespa): exame da adequação como referência para aperfeiçoamento da gestão sustentável das empresas e para formação de carteiras de investimento orientadas por princípios de sustentabilidade corporativa. Dissertação de Mestrado em Administração, Instituto COPPEAD de Administração, Universidade Federal do Rio de Janeiro, 2007. Disponível em: < www.coppead.ufrj.br/upload/publicacoes/Paulo_Barbosa.pdf>. Acesso em: 09 out. 2018.

CLARO, Priscila Borin de Oliveira; CLARO, Danny Pimentel; AMÂNCIO, Robson. Entendendo o conceito de sustentabilidade nas organizações. Revista de Administração da Universidade de São Paulo - RAUSP, São Paulo, v. 43, n. 4, p. 289-300, out./dez. 2008.

COOPER, Donald R.; SCHINDLER, Pamela S. Métodos de pesquisa em administração. 7. ed. Porto Alegre: Bookman, 2003.

FACHINI, Cristina. Sustentabilidade financeira e custos de transação em uma organização de microcrédito no Brasil. Dissertação de Mestrado em Economia. Escola Superior de Agricultura "Luiz de Queiroz", Universidade de São Paulo, Piracicaba/SP, 2005. $131 \mathrm{p}$.

FERNANDES, Miriane de Almeida. Sustentabilidade financeira - Proposta de indicador de sustentabilidade financeira aplicável às micro e pequenas empresas. Dissertação de Mestrado em Administração. Faculdade Campo Limpo Paulista - FACCAMP. Campo Limpo Paulista/SP, 2011. 39 p.

FERNANDES, Miriane Almeida; MEIRELES, Manuel. Justificativa e proposta de indicador de sustentabilidade financeira. Revista Contemporânea de Contabilidade. Universidade Federal de Santa Catarina, Florianópolis, v. 10, n. 20, p. 75-96, maio/ago. $2013 . \quad$ Disponível em:

https://periodicos.ufsc.br/index.php/contabilidade/article/view/2175-

8069.2013v10n20p75>. Acesso em: 16 out. 2018.

FONSECA, Rosimar Aparecida da. Sustentabilidade financeira em micro e pequenas empresas do município de Itabira- MG. Dissertação (Mestrado em Administração) Faculdade Novos Horizontes, Belo Horizonte, 2015.

HAIR JR., Joseph F. et al. Fundamentos de métodos de pesquisa em administração. Porto Alegre: Bookman, 2005.

KRÜGER, Roseli Fistarol. Visão da sustentabilidade empresarial: um estudo em pequenas e médias empresas industriais de Ijuí/RS. Dissertação (Mestrado em Desenvolvimento) - Universidade Regional do Noroeste do Estado do Rio Grande do Sul, Ijuí, 2016. 
LEMES JÚNIOR, Antônio Barbosa; PISA, Beatriz Jackiu. Administrando micro e pequenas empresas. Rio de Janeiro: Elsevier, 2010.

MATTAROZZI, Victorio. Os desafios do setor financeiro no caminho do desenvolvimento sustentável. In: ALMEIDA, Fernando (Org.). Desenvolvimento sustentável, 2012-2050: visão, rumos e contradições. Rio de Janeiro: Elsevier, 2012, p. 47-62.

MATIAS, Alberto Borges (Coord.). Finanças corporativas de curto prazo: a gestão do valor do capital de giro. São Paulo: Atlas, 2007.

MATIAS, Alberto Borges (Coord.). Finanças corporativas de longo prazo: criação de valor com sustentabilidade financeira. São Paulo: Atlas, 2007b. 320 p.

MARCONI, Marina de Andrade; LAKATOS, Eva Maria. Fundamentos de metodologia científica. 7. ed. São Paulo: Atlas, 2010.

MOREIRA, Hudson Soares Athayde. Gestão Empreendedora e fatores de sustentabilidade financeira do pequeno varejo supermercadista da região metropolitana de Belo Horizonte. Dissertação (Mestrado em Administração) - Faculdade Novos Horizontes, Belo Horizonte, 2014.

AMATO NETO, João. Os desafios da produção e do consumo sob novos padrões sociais e ambientais. In: AMATO NETO, João (Org.). Sustentabilidade e produção. São Paulo: Atlas, 2011, p. 01-12.

NAKAGAWA, Marcelo. Plano de negócio sustentável: princípios, conceitos e aplicações. In: AMATO NETO, João (Org.). Sustentabilidade e produção. São Paulo: Atlas, 2011, p. 113-136.

OLIVEIRA, Donizete Cosme. A Importância do Planejamento Financeiro. Revista Intellectus, Ano VIII, n. 20, p. 75-83.

SANTOS, Marcos Igor da Costa. Proposta de implantação do fluxo de caixa em uma empresa de ferragens. Caderno Profissional de Administração - UNIMEP, Alagoas, v.7, n.2, 2017.

SOUZA, Gutemberg. Organização empresarial e sustentabilidade financeira: estudo de caso em granjas suínas localizadas no Vale do Piranga - MG. Dissertação (Mestrado em Administração) - Faculdade Novos Horizontes, Belo Horizonte, 2017.

VENTURINI, Lauren Dal Bem; LOPES, Luís Felipe Dias. O modelo triple Bottom Line e a sustentabilidade na Administração Pública: pequenas práticas que fazem a diferença. Universidade Federal de Santa Maria, 2015. Disponível em: <https://repositorio.ufsm.br/bitstream/handle/1/11691/Venturini_Lauren_Dal_Bem.pdf? sequence=1\&isAllowed=y $>$. Acesso em: 11 set. 2018. 